\title{
INFECÇÃO INTRA-UTERINA E EVOLUÇÃO DA IMUNIDADE PASSIVA CONTRA O PARVOVÍRUS BOVINO'
}

\author{
Silvia de Oliveira Hübner, ${ }^{2}$ Rudi Weiblen, ${ }^{3}$ Beatriz Inês Holdefer, ${ }^{4}$ Adriana Moraes \\ da Silva, ${ }^{5}$ Mauro Pires Moraes ${ }^{6}$
}

\section{RESUMO}

Determinou-se a frequência de infecção intra-uterina pelo parvovírus bovino (BPV) através de análise de amostras de soro de terneiras coletadas antes da ingestão de colostro. Para determinar-se a evolução dos anticorpos colostrais contra o BPV, amostras de soro também foram coletadas às 6,12 e 24 horas após o nascimento, semanalmente, do $7^{\circ}$ até o $63^{\circ}$ dias de idade, e depois mensalmente, até 180 dias. $\mathrm{O}$ estudo foi realizado através do teste de inibição da hemaglutinação (HI). Os testes revelaram uma taxa de $100,0 \%$ (40/40) de infecção intra-uterina. Os anticorpos colostrais contra o BPV mantiveram-se em níveis detectáveis até o final do experimento.

UNITERMOS: Parvovírus bovino. Infecção intra-uterina. Imunidade colostral.

\section{INTRODUÇÃO}

Apesar de relatos de isolamento de parvovírus bovino (BPV) a partir de fezes de bovinos sadios $(1,35,20)$, a maioria das identificações do vírus estão associadas a doenças entéricas em neonatos ou bovinos jovens $(4,16,28,14,34)$. O vírus está ainda correlacionado com hipoplasia cerebelar congênita (5), com problemas reprodutivos (tais como aumento na taxa de mortalidade embrionária3 e abortos $(27,5,6,31)$ e com doenças respiratórias em bovinos $(29,17,33,34)$. A capacidade de o BPV nesta espécie induzir doenças não foi ainda completamente

1 Parte do trabalho de tese do primeiro autor, apresentada ao curso de Pós-graduação em Medicina Veterinária, na área de Medicina Veterinária Preventiva, Universidade Federal de Santa Maria, UFSM.

2 Médica Veterinária, MSc, Depto. de Medicina Veterinária Preventiva, UFSM.

3 Médico Veterinário, PhD, Professor Titular do Depto. de Medicina Veterinária Preventiva, Microbiologia e Parasitologia, UFSM, 97119-900, Santa Maria, RS. FAX (055) 226 2347. E-mail:

RUDI@CRETA.CCR.UFSM.BR, bolsista do CNPq. Autor para correspondência.

4 Acadêmica de Medicina Veterinária, UFSM, bolsista de Iniciação Científica do CNPq.

5 Médico Veterinário, Pós-graduando em Medicina Veterinária, UFSM.

Recebido para publicaç̃̃o em 31/05/96. Revisto em 25/09/96. Aceito em 20/12/96. 
HUBNER,S.O.; WEIBLEN, R.; HOLDEFER, B.I.; SILVA, A.M.; MORAES, M.P. Infecção intra-uterina evoluçto da imunidade passiva contra o parvovírus bovino. Rev. Pat. Trop.25 ( 2 ): 263-271, jul./dez. 1996

assegurada. Aparentemente, a patogenicidade do BPV depende de outros fatores, como problemas de manejo, situações estressantes, privação de colostro e infecções concomitantes (32).

No Brasil ainda não há descrição de isolamento de BPV, porém Holdefer et l., (15) ao realizarem um inquérito sorológico abrangendo várias bacias leiteiras do estado do Rio Grande do Sul, encontraram $97,7 \%$ de bovinos com anticorpos contra o BPV, comprovando que o vírus está amplamente disseminado no rebanho leiteiro desse estado. A falha e o pequeno número de isolamentos de BPV talvez devam-se ao uso de soro fetal bovino contendo pequenas quantidades de anticorpos específicos para suplementar os meios de cultura, ou ao uso de cultivos celulares inadequados (26).

Evidência de ocorrência de infecção intra-uterina pelo BPV foi relatada primeiramente por Storz et al. (26). Posteriormente, vários pesquisadores demonstraram a presença de anticorpos para o BPV no soro de terneiros privados da ingestão de colostro $(16,23,30,19,31)$. A infecção fetal antes da imunocompetência pode levar a sérias conseqüências, como morte fetal ou aborto $(22,26,31)$. O perigo de aparecimento de doenças correlacionadas ao BPV é maior quando o rebanho sofre a infecção primária. A alta prevalência de bovinos com anticorpos para BPV fornece condições para a proteção passiva dos neonatos. Há poucas informaçð̃es sobre a duração da imunidade colostral para o BPV (26).

Considerando que o BPV pode ser um agente determinante de diarréia neonatal, problemas reprodutivos e respiratórios, este trabalho teve como meta obter informaçб̃es sobre a ocorrência de transmissão intra-uterina e determinar a evolução dos anticorpos para o BPV adquiridos passivamente, via ingestão de colostro, nas condiçб̃es de criação de bovinos leiteiros da região central do estado do Rio Grande do Sul.

\section{MATERIAL E MÉTODO}

\section{Animais de experimentação}

Vacas da raça Holandesa, com diferentes idades e próximas do parto, e suas respectivas filhas, foram utilizadas no experimento. Os bovinos eram provenientes de uma propriedade produtora de leite tipo B da região central do estado do Rio Grande do Sul. Somente fêmeas foram incluídas, pois o manejo da propriedade determina que os machos sejam descartados logo após o nascimento. O manejo local também determina que após o nascimento as terneiras sejam retiradas das suas mães e colocadas em terneireiras individuais. Para assegurar a ingestão de colostro, era fornecido um pool desse alimento nos dois primeiros dias de vida. A partir de então, os animais recebiam uma mistura de leite in natura de várias vacas e,
HƯBNER,S.O.; WEIBLEN, R.; HOLDEFER, B.I.; SILVA, A.M.; MORAES, M.P. Infecção intra-uterina e evolução da imunidade passiva contra o parvovírus bovino. Rev. Pat. Trop.25 ( 2 ): 263-271, jul./dez. 1996

gradativamente, o concentrado e o feno iam sendo incluídos na dieta. Aproximadamente aos dois meses de idade efetuava-se o desmame e então as terneiras eram conduzidas para piquetes com até seis animais.

\section{Material para exames}

Foram coletadas amostras de sangue mediante punção da veia jugular, com agulhas $40 \times 20$, ou dos vasos caudais, utilizando tubos de ensaio a vácuo. As amostras eram devidamente identificadas e, após a coleta, mantidas em posição inclinada ou submetidas à centrifugação, para retração do coágulo e separação do soro. Posteriormente, as amostras de soro eram transferidas para outros frascos, aquecidas em banho-maria a $56^{\circ} \mathrm{C}$ durante 30 minutos, visando inativar o complemento, e então estocadas a $-18^{\circ} \mathrm{C}$ até a execução do teste.

As coletas eram realizadas periodicamente. Para verificar o status de infecção para o parvovírus bovino (BPV) nas vacas, foram analisadas amostras de soro retiradas aproximadamente aos 28 dias antes do parto. Foram analisadas 40 amostras de soro, para verificar a prevalência de anticorpos entre as vacas deste rebanho leiteiro, e 415 amostras de soro correspondentes a coletas preestabelecidas de 40 terneiras que apresentaram-se soropositivas após a ingestão de colostro. Nas terneiras a retirada de sangue foi feita logo após o nascimento, antes da ingestão do colostro, para obter-se resultados sobre infecção pré-natal. Posteriormente, a coleta foi realizada às 6,12 e 24 horas após a ingestão do colostro; semanalmente, até os 63 dias; aos 90,120, 150 e 180 dias de idade, para assim determinar a evolução dos anticorpos colostrais contra o BPV.

\section{Método sorológico}

Inibição da hemaglutinação (HI)

$\mathrm{O}$ teste de inibição da hemaglutinação (HI) foi realizado para detectar anticorpos contra o BPV, segundo técnica descrita por Weiblen (32), com algumas modificações. Retirada uma alíquota de $0,1 \mathrm{ml}$ de cada amostra, adsorveu-se com 0,1 $\mathrm{ml}$ de hemácias de cobaia a $50 \%$, durante uma hora, a $4^{\circ} \mathrm{C}$, para ser utilizada até quatro dias após a colheita. Depois de adsorvidos com hemácias, adicionaram-se 0,8 $\mathrm{ml}$ de PBS (Solução Salina Fosfatada), centrifugou-se a mistura e o sobrenadante foi armazenado a $-18^{\circ} \mathrm{C}$ em frascos de vidro. Foi então adicionado antígeno viral com quatro unidades hemaglutinantes, mais incubação das microplacas à temperatura ambiente durante 30 minutos, adição de hemácias de cobaia a $1 \%$ e leitura registrada após aproximadamente 12 horas de repouso à temperatura de $4^{\circ} \mathrm{C}$. $\mathrm{O}$ antígeno viral foi preparado em células Madin-Darby bovine kidney (MDBK) e pulmão de feto bovino. Como controle sorológico positivo, foi utilizado soro hiperimune, obtido após inoculações sucessivas em coelhos, via intramuscular, e soro bovino fetal 
HOOBNER,S.O.; WEIBLEN, R.; HOLDEFER, B.I.; SILVA, A.M.; MORAES, M.P. Infecção intra-uterina e evoluçăo da imunidade passiva contra o parvovírus bovino. Rev. Pat. Trop.25 ( 2 ): 263-271, jul./dez. 1996

(SBF), previamente testado, como controle negativo. A leitura era registrada após a manutenção das microplacas à temperatura de $4^{\circ} \mathrm{C}$, durante aproximadamente 12 horas. O título considerado foi a maior diluição de soro, em que houve completa inibição da hemaglutinação, na presença de quatro unidades hemaglutinantes. Os resultados somente eram considerados válidos quando o título do controle positivo e do SBF variavam em apenas um título e na mesma direção.

\section{Análise estatística}

Para verificar a evolução dos anticorpos para BPV e a correlação entre os títulos de anticorpos das terneiras e de suas mães, foi utilizado o método de regressão, conforme descrito por Steel \& Torrie (25).

\section{RESULTADOS E DISCUSSÃO}

A presença de anticorpos contra o BPV nas vacas do rebanho leiteiro deste estudo, determinada através da prova de HI, ocorreu em $100 \%$ dos animais (40/40). Holdefer et al. já haviam descrito altas taxas de prevalência de anticorpos, demonstrando a presença do BPV na região mesma deste estudo (15). Todos os bezerros destas vacas nasceram com anticorpos para BPV, com títulos variando de 1:10 a 1:640. O título médio geométrico de anticorpos (GMT) contra o BPV, no soro de 40 terneiras em que fez-se coletas seriadas de soro desde a ingestão de colostro até os 180 dias de vida, é apresentado na Figura 1. Quando os dados obtidos foram submetidos à análise de regressão, não houve correlação entre os títulos de anticorpos e a idade dos animais, ou seja, o GMT não variou em função da idade.

As amostras de soro das terneiras analisadas para a presença de anticorpos contra o parvovírus bovino (BPV), com história de privação de colostro, apresentaram $100 \%$ de positividade. Storz et al. (26) e Huck \& Woods (16) já haviam relatado a existência de anticorpos contra o BPV em amostras de soro fetal e pré-colostral, porém não revelaram a freqüência de ocorrência e nem quantificaram estes anticorpos. Os resultados do presente estudo estão de acordo com o trabalho de Tokuhisa et al. (30) que, ao examinarem 11 amostras de soro pré-colostral e 14 amostras de soro fetal, encontraram anticorpos contra o BPV em $100 \%$ destas. Resultados semelhantes também foram obtidos por Sato et al. (23) ao pesquisarem a presença de anticorpos contra o BPV em soro de fetos bovinos clinicamente normais, em amostras pré-colostrais. Através de análise pela prova de inibição da
HÜBNER,S.O.; WEIBLEN, R; HOLDEFER, B.I; SILVA, A.M ; MORAES, M.P. Infecç̃o intra-uterina e evolução da imunidade passiva contra o parvovírus bovino. Rev. Pat. Trop.25 ( 2 ): 263-271, jul./dez. 1996

hemaglutinação (HI), 100\% (37/37) apresentaram anticorpos antes da ingestão do colostro e $86,6 \%$ (39/45), usando a prova de soro-neutralização.

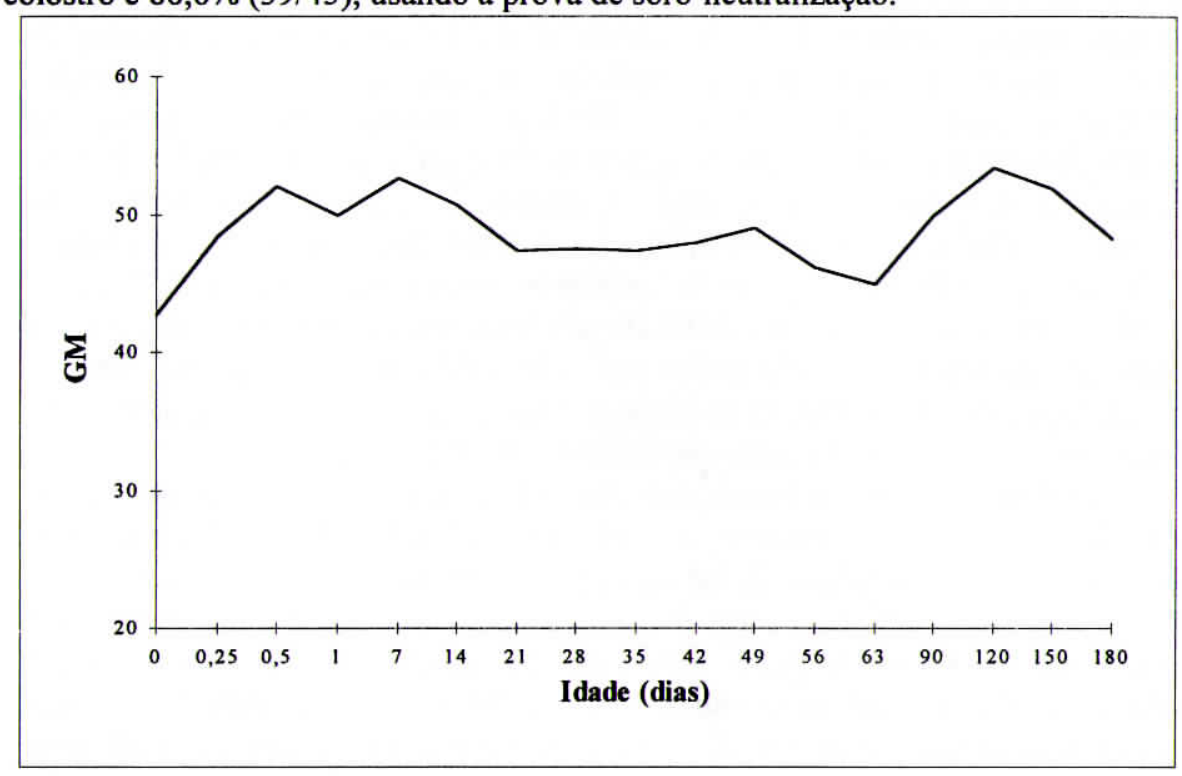

Figura 1. Evolução do título médio geométrico de anticorpos (GMT) contra o parvovírus bovino (BPV) em amostras de soro de 40 terneiras, desde a ingestão de colostro até o $180^{\circ}$ dia de idade, medido através da prova de inibição da hemaglutinação (HI)

Dentre os 12 fetos estudados por HI, 11 possuíam anticorpos, com títulos que variavam de 1:2 a 1:512. Conforme o estudo realizado por Virakul et al. (31), foram encontrados anticorpos contra o BPV em 99 de 110 (90\%) amostras de soro de fetos testados pela prova de HI, e em $35(31,8 \%)$ testados por soro-neutralização.

Embora a prova de HI seja muito utilizada para detectar bovinos com anticorpos contra o $\operatorname{BPV}(2,26,10)$, parece possuir menos especificidade quando comparada à soro-neutralização. Por outro lado, há indicações da existência de alguma substância, que não imunoglobulina, capaz de inibir a replicação do BPV e, assim, influenciar os resultados obtidos pela prova de soro-neutralização (30). Somente um animal apresentou título de anticorpos baixo (1:10), talvez devido à presença em seu soro de tais inibidores inespecíficos e não à infecção intra-uterina. 
HƯBNER,S.O.; WEIBLEN, R.; HOLDEFER, B.I.; SILVA, A.M.; MORAES, M.P. Infecção intra-uterina e evoluçăo da imunidade passiva contra o parvovírus bovino. Rev. Pat. Trop.25 ( 2 ): 263-271, jul./dez. 1996

Lucas et al. (21) utilizaram as provas de imunofluorescência indireta e direta para detectar a presença de anticorpos e antígenos virais em fluidos e tecidos de fetos abortados, respectivamente. Embora tenham analisado um expressivo número de amostras, nenhuma apresentou-se positiva, o que contraria os resultados apresentados pelos outros autores. Deve-se lembrar que a prova de imunofluorescência é considerada de alta especificidade e não é influenciada pela presença de inibidores inespecíficos, hemólise, contaminação bacteriana ou toxicidade. Talvez a ausência de anticorpos nos fetos deva-se a infecção durante o período em que não são capazes de responder imunologicamente $(22,26,24)$. Segundo Storz et al. (26), a suscetibilidade dos fetos bovinos ao BPV é dependente da idade em que sofrem infecção, sendo que os fetos do primeiro e segundo trimestre de gestação podem não responder ao estímulo antigênico. Alguns pesquisadores (31) já descreveram fetos com três meses produzindo anticorpos contra BPV.

Os dados apresentados neste trabalho indicam que os fetos foram capazes de desenvolver uma resposta imunológica após infecção pelo BPV, produzindo altos títulos de anticorpos inibidores da hemaglutinação. Aparentemente, a infecção pelo BPV não tem efeito inibitório sobre o funcionamento do sistema imunológico. Tal afirmação encontra respaldo nos trabalhos de Storz et al. (26), Liggitt et al. (19) e Hayder et al., (13) os quais demonstraram que os fetos bovinos podem desenvolver altos títulos de anticorpos dentro de 10 dias após a infecção, o que provavelmente contribui para a eliminação do vírus, a recuperação da infecção e o nascimento de animais sem infecção.

Ao quantificar-se os anticorpos para BPV no soro das terneiras com uma semana de vida, verificou-se que não houve correlação com os títulos de anticorpos, no $28^{\circ}$ dia pré-parto, de suas mães correspondentes. Para esta análise, utilizou-se o método de correlação. Provavelmente isto ocorreu porque o tempo para sucção de colostro de suas mães era muito reduzido, devido à separação logo após o nascimento. Terneiros que não ingerem colostro de suas mães até seis horas após o nascimento adquirem baixas concentraçбes de imunoglobulinas séricas (11). Outra causa provável seria o fornecimento de um pool de colostro durante os primeiros dois dias de vida. Apesar de não ter sido realizada a titulação de anticorpos nos colostros oferecidos, ou a determinação da concentração de imunoglobulinas, suporese que o pool não era equivalente ao colostro de suas mães.

Os dados obtidos sobre a evolução dos anticorpos colostrais para o BPV, ao serem submetidos à análise de regressão (Figura 1), mostraram que não houve tendencia significativa ao desaparecimeto dos anticorpos até $0180^{\circ}$ dia pósnascimento (idade do último teste). Anticorpos produzidos ativamente para o BPV foram detectados antes da perda total dos anticorpos passivos maternos $(8,9)$. $O$ início da produção de anticorpos provavelmente deve-se à exposição a um meio
HÜBNER,S.O.; WEIBLEN, R.; HOLDEFER, B.I.; SILVA, A.M.; MORAES, M.P. Infecção intra-uterin e evolução da imunidade passiva contra o parvovírus bovino. Rev. Pat. Trop.25 ( 2 ): 263-271, jul./dez 1996

ambiente contaminado, devido à eliminação do vírus nas fezes (27) e sua grande resistência fora do hospedeiro (12), fazendo com que o desafio antigênico realize uma constante estimulação na produção de anticorpos específicos. Durham et al., (7) trabalhando com animais isolados, registraram um declínio progressivo nos níveis de anticorpos colostrais contra o BPV. Porém, terneiros com mais de 29 semanas de idade ainda mostravam persistência de atividade inibidora de hemaglutinação em baixo nível, o que postulam ser devido a inibidores inespecíficos. Esses resultados contrariam Klatt (18), o qual afirma que a imunidade materna desaparece entre três a cinco meses de idade, quando os animais seriam suscetíveis ao aparecimento de doenças causadas pelo BPV. Os registros sobre a ocorrência de diarréias neste estudo limitaram-se, na grande maioria das vezes, ao período entre duas ou três primeiras semanas de vida, e provavelmente foram devido à troca de alimentação. Raros foram os registros de surgimento de doenças respiratórias, e quando existentes, foram auto limitantes. Além disso, não houve a soroconversão que se faz necessária para detectar uma infecção ativa por BPV (12).

Pelos dados aqui obtidos conclui-se que a alta prevalência de anticorpos para o BPV deste rebanho leiteiro (100\%) e de todo o estado do Rio Grande do Sul (15) restringe a possibilidade do surgimento de infecção nos neonatos ocasionadas por esse vírus, pois cria condições para proteção nesta fase de grande suscetibilidade.

\section{SUMMARY}

Intrauterine infection and evolution of passive immunity against bovine parvovirus

Sera samples from female calves were collected before the ingestion of colostrum for the determination of intrauterine infection by bovine parvovirus (BPV). Sera samples were also collected 6, 12 and 24 hours after birth, weekly from the 7 th to the 63 th day, and after that until 180 days, for the study of the evolution of the colostrum antibodies level. The haemaglutination inhibition test was used for this study. The tests showed an intra-uterine infection rate of $100 \%(40 / 40)$. The colostrum antibodies against the BPV were kept in detectable levels up to the end of the experiment.

KEYWORDS: Bovine parvovirus. Intrauterine infection. Colostral immunity. 
HUOBNER,S.O.; WEIBLEN, R.; HOLDEFER, B.I.; SILVA, A.M.; MORAES, M.P. Infecção intra-uterina c evoluçăo da imunidade passiva contra o parvovírus bovino. Rev. Pat. Trop.25 ( 2 ): 263-271, jul./dez. 1996

\section{REFERÊNCIAS BIBLIOGRÁFICAS}

01.Abinanti, F.R., Warfield, M.S. Recovery of a hemadsorbing virus (HADEN) from the gastrointestinal tract of calves. Virology, 14: 288-289, 1961.

02.Bachmann, P. A. Properties of a bovine parvovirus. J. Vet. Med. [B], 18: 80-85, 1971.

03.Barnes, M.A., Wright, R.E., Bodine, A.B. et al. Frequency of bluetongue and bovine parvovirus infection in cattle in South Carolina dairy herds. Am. J. Vet. Res., 43: 1078-1080, 1982.

04.Bates, R.C., Storz, J., Reed, D.E. Isolation and comparison of Bovine Parvoviruses. J. Infec. Dis., I26: $5,1972$.

05.Barros, C.S.L. Pathology of experimental infection of the bovine fetus with bovine parvovirus. Fort Collins, 1980. Thesis (Doctor of Philosophy in Veterinary Medical Science) - Colorado State University, 1980, 199p.

06.Bodine, A.B., Alberty, C.F., Buck, C.S. et al. Possible immuno-protection of the bovine parvovirus in the uterus: preliminary communication. Theriogenology, 16: 201-204, 1981

07.Durham, P.J.K., Lax, A., Johnson, R.H. Pathological and virological studies of experimental parvoviral enteritis in calves. Res. Vet. Sci., 38: 209-219, 1985.

08.Durham, P.J.K., Johnson, R.H., Isles, H. et al. Epidemiological studies of parvovirus infections in calves an endemically infected properties. Res. Vet. Sci., 38: 234-240, 1985.

09.Durham, P.J.K., Johnson, R.H., Parker, R.J. Exacerbation of experimental parvoviral enteritis in calves by coccidia and weaning stress. Res. Vet. Sci., 39: 16-23, 1985.

10.Durham, P.J.K., Johnison, R.H. Properties of an Australian isolate of bovine parvovirus type 1. Vet. Microbiol., 10: 335-345, 1985d.

11.Edwards, S.A., Broom, D.M. Behavioral interaction of dairy cows with their newborn calves and the effect of parity. Anim. Behav., 30: 525-535, 1982.

12.Fenner, F., Bachmann, A., Gibbs, E.P.J. et al. Veterinary Virology. New York: Academic Press, 1993. Cap. 16. Parvoviridae. p.307-319.

13.Hayder, H.A., Storz, J., Young, S. Antigenicity of bovine parvovirus in fetal infections. Am. J. Vet. Res., 44: 558-563, 1983.

14.Hofmann, W., Arens, M. Corona-Rota-und parvovirusinfektionen beim kalb aus klinisher. Deut. Tierär. Wochens., 88: 316-321, 1981.

15.Holdefer, B.I. Hubner, S.O., Weiblen, R. Parvovirus bovino: inquérito soro-epidemiológico no rebanho leiteiro do RS. In: Jornada integrada de pesquisa extensão e ensino. Universidade Federal de Santa Maria, 1994. p. 393.

16.Huck, R.A., Woods, D.W. Isolation of a bovine parvovirus in the United Kingdom. Vet. Rec., 36 : $155-156,1975$.

17.Inaba, Y., Kurogi, E., Takahashi, E. et al. Isolation and properties of bovine parvovirus type 1 from Japanese calves. Archv. für Gesamte Virusforshung, 42: 54-66, 1973.

18.Klatt, E. Serological, diagnostic studies on the involvement of bovine coronavirus, parvovirus, rotavirus, bovine virus, diarrhoea virus, parainfluenza virus type 3 and IBR IPV virus infections in respiratory diseases of cattle. Justus-Liebig, 1988. 84p. Thesis (Doctor of Philosophy in Veterinary respiratory diseases of cattle. Justus-Liebig, 1988.

19.Liggitt, H.D., DeMartini, J.C., Pearson, L.D. Immunologic responses of the bovine fetus to parvovirus infection. Am. J. Vet. Res., 43: 1355-1359, 1982.

20.Lucas, M.H., Westcott, D.G.F. Bovine Parvovirus. Vet. Rec., 116: 698, 1985

21.Lucas, M.H., Westcott, D.G.F., Edwards, S. et al. Immunofluorescence and cell culture techniques in the diagnosis of viral infection of aborted bovine fetuses. Vet. Rec., 118: 242-243, 1986.

22.Usburn, B.I. Immune responsiveness of the fetus and neonate. J. Am. Vet. Med. Assoc., 163: 801803,1973 .
HÜBNER S.O; WEIBLEN, R ; HOLDEFER, B I; SILVA, A M ; MORAES, M P Infecç̃o intra-uterina e evolução da imunidade passiva contra o parvovírus bovino. Rev. Pat. Trop.25 ( 2 ): 263-271, jul./dez. 1996

23.Sato, K., Inaba, Y., Tokuhisa, S. et al. Antibodies against several viruses in sera from normal bovine fetuses and precolostral calves. Natl. Inst. Anim. Health, 20: 77-78, 1980.

24.Schultz R.D. Comments on the Immune Response of the Fetus and Neonate. J. Am. Vet. Med. Assoc. 163: 804-806, 1973.

25.Steel, R.G.D., Torrie, J.H. Principles and procedures of statistics - A biometrical approach. New York: McGraw-Hill, 1980. 633p.

26.Storz, J., Bates, R.C., Warren, G.S. et al. Distribution of antibodies against bovine parvovirus 1 in cattle and other animal species. Am. J. Vet. Res., 33: 269-272, 1972.

27.Storz, J., Young, S., Carrol. E.J. et al. Parvovirus infection of the bovine fetus: Distribution of infection, antibody response, and aged-related susceptibility. Am. J. Vet. Res., 39: 1099-1102, 1978.

28.Storz, J., Leary, J.J., Carlson, J.H. et al. Parvoviruses associated with diarrhea in calves. J. Am. Vet Med. Assoc., 173: 624-627, 1978.

29.Spahn, J.G., Mohanty, S.B., Hetrick, F.M. Experimental infection of calves with hemadsorbin enteric (HADEN) virus. Cornell Vet., 56: 377-386, 1966.

30. Tokuhisa, S. Inaba, $\mathrm{Y}$. Sato, $\mathrm{K}$. et al. Inhibitors of bovine parvovirus, coronavirus and rotavirus in precolostral and fetal bovine sera. Vet. Microbiol., 6: 143-155, 1981.

31.Virakul, P., Vahdat, F., Joo, H.S. et al. Prevalence of antibodies to specific infectious agents in bovine fetuses from a slaughterhouse in Minnesota. Theriogenology, 23: 679-686, 1985.

32.Weiblen, R. Infectivity and epidemiological studies on bovine parvovirus. Urbana, 1983. Thesis (Doctor of Philosophy in Veterinary Science) - Graduate College of the University of Illinois, 1983, 212p.

33. Weiblen, R. Mock, R.E. Woods, G.T. et al. Possible involvement of bovine parvovirus in the respiratory disease complex. In: International Symposium of Veterinary Laboratory Diagnostic, 1983. Ames, Iowa. Proceedings, World Association of Veterinary Laboratory Diagnosticians, 361$367,1983$.

34.Weiblen, R., Niock, R.E., Woods, G.T. et al. Bovine Parvovirus infection. In: International Symposium of Veterinary Laboratory Diagnostic, 1983. Ames, Iowa. Proceedings, World Association of Veterinary Laboratory Diagnosticians, 369-376, 1983.

35. Wost, L.O., Johnson, R.H., Goodchield, I. et al. Isolation of bovine parvovirus type 1 in Australia Austr. Vet. J., 55: 199-200, 1979. 